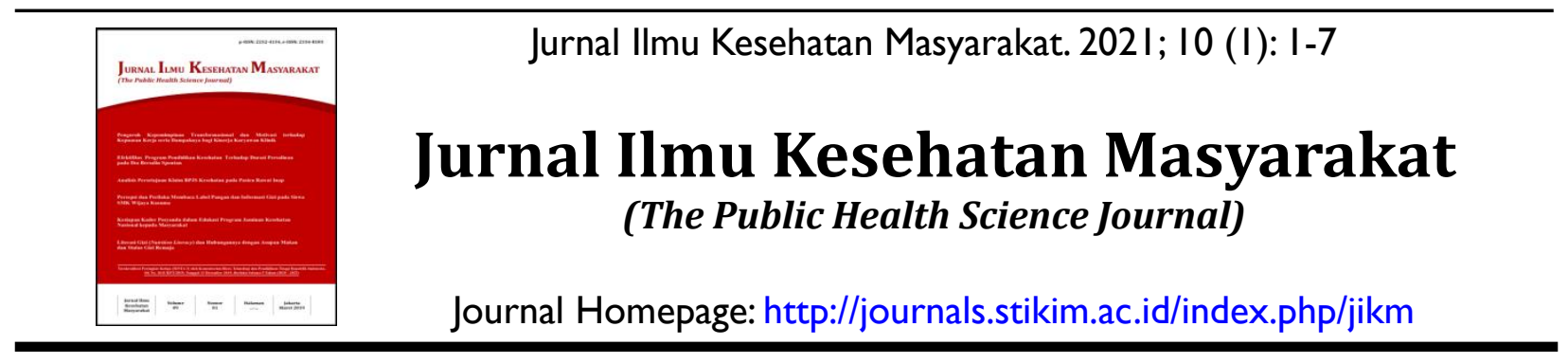

\title{
Efektifitas Pijat Oksitosin dan Aromaterapi Lavender terhadap Keberhasilan Relaktasi pada Ibu Nifas
}

\author{
Siti Rafika Putri ${ }^{1}$, Rahmawati ${ }^{2}$ \\ 1,2Program Studi Kebidanan, Akademi Kebidanan Al-Ikhlas, \\ Jl.Hankam Desa Djogjogan Kecamatan Cisarua Kabupaten Bogor \\ Email: sitirafikaputri@yahoo.co.id', rahmawati.rumaisya@yahoo.com²
}

\begin{abstract}
Abstrak
Relaktasi adalah suatu proses kembalinya menyusui setelah berhentinya menyusui dan kembali menyusui secara eksklusif. Penelitian ini sangat penting mengingat tehnik pijat oksitosin dan aromaterapi lavender dapat meningkatkan keberhasilan relaktasi agar bayi mendapatkan ASI kembali, sehingga kebutuhan nutrisi bayi terpenuhi dan bayi dapat tumbuh kembang dapat optimal dan juga mendukung perkembangan imunitas bayi. Tujuan penelitian ini adalah untuk mengetahui efektivitas pijat oksitosin dan aroma terapi lavender terhadap keberhasilan relaktasi pada ibu nifas. Jenis penelitian ini adalah penelitian experiment. Desain penelitian one group pretest post-test. Jumlah populasi dan sampel dalam penelitian ini adalah seluruh ibu nifas di BPM Hj. Elly Liawati Kabupaten Bogor pada Bulan April-September Tahun 2020 sebanyak 22 responden. Hasil analisis uji Wilcoxon, diperoleh nilai $p$ value $0,000(p-v a l u e=0,000<0,05)$ menunjukka ada pengaruh pemberian pijat oksitosin dengan aromaterapi lavender terhadap keberhasilan relaktasi pada ibu postpartum ( $\mathrm{Pv}=0,000)$. Penelitian ini membuktikan bahwa terapi pijat oksitosin dan aromaterapi lavender dapat meningkatkan angka keberhasilan relaktasi sehingga bayi dapat memperoleh ASI kembali. Oleh karena itu, peningkatan pengetahuan tentang relaktasi sangatlah penting sehingga dapat meningkatkan pemberian ASI.
\end{abstract}

Kata Kunci: Aromaterapi, ASI, lavender, pijat oksitosin, relaktasi

\begin{abstract}
Relactation is a process of returning after stopping breastfeeding and returning to exclusive breastfeeding. Breast milk contains a variety of essential and complete nutrients to meet the nutritional needs of babies so that growth and development can be optimal and also supports the development of infant immunity, therefore babies really need to produce breast milk in sufficient quantities. Based on the health profile of the West Java Health Office in 2018 the level of exclusive breastfeeding in the province of West Java is $53 \%$, this coverage is still very far from the national target of $80 \%$. The purpose of this study was to determine the effectiveness of oxytocin massage and aroma of lavender therapy on the success of lactation in postpartum mothers. This type of research is experimental research. One group pretest posttest research design. The total population and sample in this study were all postpartum mothers at BPM Hj.Elly Liawati Bogor Regency from April to September 2020 as many as 22 respondents The results of the Wilcoxon test analysis showed a $p$ value of 0,000 ( $p$-value $=0,000<0.05)$, indicating that there was an effect of giving oxytocin massage with lavender aromatherapy on the success of relactation in postpartum mothers $(P v=0,000)$. This study proves that oxytocin massage therapy and lavender aromatherapy can increase the success rate of relactation so that babies can get breast milk again. Therefore, up knowledge about relactation is very important so that it can increase breastfeeding.
\end{abstract}

Keywords: Aromatherapy, breastfeeding, lavender, oxytocin massage, relaxation 


\section{Pendahuluan}

Relaktasi adalah suatu proses kembalinya menyusui setelah berhentinya menyusui dan kembali menyusui secara ekslusif. Relaktasi merupakan suatu kondisi dimana wanita yang telah berhenti menyusui anaknya, baru atau sudah lama berhenti, dapat melanjutkan produksi air susunya untuk anak kandung sendiri maupun anak adopsi bahkan tanpa didahului kehamilan terlebih dahulu. Tingkat keberhasilan relaktasi tinggi pada usia kurang dari 3 bulan akan tetapi pada bayi usia kurang dari 8 minggu akan lebih mudah melekat pada payudara. ${ }^{1}$

World Health Organization (WHO) merekomendasikan pemberian ASI eksklusif selama 6 bulan pertama setelah bayi lahir ditambah dengan MP-ASI atau makanan pendamping ASI sampai usia 2 tahun. ${ }^{2}$ American Academy of Pediatrics (AAP), Academy of Breasfeeding Medicine (ABM) dan Ikatan Dokter Anak Indonesia (IDAI) merekomendasikan hal yang sama tentang pemberian ASI eksklusif sekurangkurangnya 6 bulan. $^{3}$ Data UNICEF tahun 2013, menyebutkan hanya $32,6 \%$ dari 136,7 juta bayi lahir di seluruh dunia yang disusui secara eksklusif selama 6 bulan pertama. Bayi yang tidak diberi ASI eksklusif di negara industri, memiliki risiko lebih besar untuk meninggal dari pada bayi yang diberi ASI ekslusif, sementara di negara berkembang hanya 39\% ibu-ibu yang memberikan ASI Ekslusif. ${ }^{4}$

Data Dinas Kesehatan Provinsi Jawa Barat tahun 2015, menyebutkan bahwa cakupan pemberian ASI 0-6 bulan sebesar $54,3 \%$, persentasi bayi yang mendapat ASI eksklusif untuk umur bayi di bawah 6 bulan sebesar $41 \%$, ASI eksklusif pada bayi berumur 4-5 bulan sebesar $27 \%$ dan melanjutkan menyusui sampai anak berumur 2 tahun sebesar 55\%. Dari data Jawa Barat tahun 2017 cakupan ASI eksklusif baru mencapai 53,0\%. Menurut kabupaten kota, kisaran cakupan ASI eksklusif pada bayi umur 0-6 bulan, terendah di Kabupaten Bandung (20,34\%) dan tertinggi di Kabupaten Tasikmalaya
(113,11\%). Sedangkan tahun 2017, cakupan ASI eksklusif di kabupaten Bogor baru mencapai $22.84 \% .^{5}$

Hasil penelitian su jin cho, et.al menyebutkan ibu yang gagal dalam melakukan proses laktasi terjadi karena ASI yang sedikit (43\%), kelelahan (14,3\%), berat badan kurang $(14,3 \%)$, puting datar $(14,3 \%)$, penolakan yang kuat dari bayi $(4,8 \%)$, hamil $(4,8 \%)$, dan tidak mendapat dukungan dari keluarga $(4,8 \%){ }^{6}$ Permasalahan tidak tercapainya pemberian ASI eksklusif salah satunya adalah karena pengeluaran ASI yang tidak lancar pada awal pasca persalinan. Penurunan produksi dan pengeluaran ASI pada hari-hari pertama setelah melahirkan dapat disebabkan oleh kurangnya rangsangan hormon prolactin dan oksitosin yang sangat berperan dalam kelancaran produksi dan pengeluaran ASI. $^{7}$

Pijat oksitosin adalah salah satu solusi untuk mengatasi tidak lancarnya produksi ASI. Pijat oksitosin dilakukan dengan cara memijat daerah punggung sepanjang kedua sisi tulang belakang yang diharapkan dengan pemijatan ini ibu akan merasa rileks. Penelitian Pilaria, dkk menyimpulkan bahwa tingkat keberhasilan pijat oksitosin dalam meningkatkan keberhasilan produksi ASI mencapai $90 \% .^{8}$ Aroma terapi lavender adalah suatu yang bisa meningkatkan gelombang alfa di dalam otak, gelombang ini bisa membuat rileks pada seseorang, dan memberikan rasa nyaman, rasa keterbukaan, mengurangi rasa tertekan, stress, rasa sakit, emosi yang tidak seimbang, hysteria, rasa frustasi dan kepanikan. Relaksasi otot halus yang disebabkan oleh pemberian aromaterapi lavender dan pengeluaran oksitosin yang meningkat akibat pemijatan oksitosin dapat dijadikan salah satu faktor keberhasilan menyusui pada proses relaktasi. ${ }^{9}$

Penelitian sebelumnya yang dilakukan oleh Zahra terkait pengaruh pijat oksitosin dan aromaterapi lavender terhadap produksi ASI pada ibu post-partum menunjukan ada pengaruh pemberian pijat oksitosin dengan aromaterapi lavender 
terhadap produksi ASI pada ibu postpartum. ${ }^{10}$ Namun, penelitian tersebut hanya melihat banyaknya jumlah produksi ASI yang dihasilkan. Oleh karena itu, penelitian ini bertujuan untuk mengetahui efektivitas pijat oksitosin dan aroma terapi lavender terhadap keberhasilan relaktasi pada ibu nifas di bidan praktek mandiri (BPM) Bidan E Ciawi Bogor Tahun 2020. Penelitian ini dilakukan karena masih tingginya angka ibu yang tidak memberikan ASI eksklusif dan rendahnya keberhasilan relaktasi.

\section{Metode}

Jenis penelitian ini adalah penelitian experiment, menggunakan desain penelitian eksperimental dengan jenis pra-experiment. Rancangan penelitian yang digunakan adalah rancangan one group pre and posttest. Penelitian ini tidak menggunakan kelas pembanding namun sudah menggunakan tes awal sehingga besarnya efek atau pengaruh penggunaan dapat diketahui secara pasti. Dalam penelitian ini, subyek penelitian terlebih dahulu diberikan tes awal (pre-test) untuk mengetahui sejauh mana kemampuan Ibu untuk melakukan relaktasi dengan cara pijat oksitosin dan aromaterapi lavender. Setelah diberikan tes awal, selanjutnya dilakukan pijat oksitosin dan aromaterapi lavender secaran rutin 3 kali seminggu selama 3 minggu. Setelah selesai melakukan pijat oksitosin dan aromaterapi lavender secaran rutin, selanjutnya kepada Ibu tersebut diberikan tes akhir (post-test) untuk mengetahui sejauh mana pengaruh pijat oksitosin dan aromaterapi lavender terhadap keberhasilan relaktasi. Dalam rancangan ini dilakukan observasi pertama (pre-test) yang memungkinkan menguji perubahanperubahan yang terjadi setelah adanya eksperimen.

Teknik pengambilan sampel pada penelitian ini adalah non-probability sampling dengan menggunakan teknik accidental sampling. Tempat penelitian ini dilakukan di BPM Hj.Elly Liawati wilayah kerja Ciawi kabupaten Bogor. Penelitian ini dilaksanakan pada bulan April-September Tahun 2020. Populasi dan sampel dalam penelitian ini adalah seluruh ibu nifas di BPM Hj.Elly Liawati Kabupaten Bogor Tahun 2020 sebanyak 22 orang. Sampel diambil dengan memenuhi kriteria inklusi dan eksklusi. Adapun kriteria inklusi yaitu, Ibu nifas hari 3 hingga hari ke 40 yang bersedia menjadi responden penelitian, ibu yang tidak memberikan ASI Eksklusif pada bayi selama penelitian berlangsung, ibu yang sedang dalam cuti kerja atau hanya beraktivitas rutin sebagai ibu rumah tangga, ibu yang melahirkan dengan umur kehamilan atterm ( $>37$ minggu) dan berat badan lahir bayi normal ( $>2500$ gram). Variabel independen adalah Pijat oksitosin dengan aromaterapi lavender dan variabel dependen adalah relaktasi. Data yang digunakan dalam penelitian ini merupakan data primer yaitu data diambil langsung dari responden di BPM $\mathrm{Hj} . \mathrm{E} 11 \mathrm{y}$ Liawati.

Instrumen yang digunakan adalah lembar SOP pijat oksitosin aromaterapi lavender, lembar observasi jumlah produksi ASI, gelas ukur, dan wadah untuk menampung ASI. Kuesioner yang digunakan telah diuji validitas dan reabilitas. Analisis data univariat diperoleh dalam bentuk distribusi frekuensi dan pada analisa bivariat digunakan metode uji statistik non parametrik yaitu uji wilxocon karena data tidak berdistribusi normal. Tingkat kepercayaan yang digunakan adalah $90 \%$ atau $\alpha=0,05$.

\section{Hasil}

Tabel 1. Distribusi Frekuensi Responden Berdasarkan Umur, Pekerjaan dan Paritas

\begin{tabular}{llcc}
\hline \multicolumn{1}{c}{ Variabel } & \multicolumn{1}{c}{ Kategori } & n & \% \\
\hline Umur (tahun) & $<20$ tahun & 2 & 9 \\
& 20-35tahun & 19 & 86,4 \\
\multirow{3}{*}{ Pekerjaan } & $>35$ tahun & 1 & 4,6 \\
\multirow{4}{*}{ Paritas } & Bekerja & 2 & 10 \\
& Tidak bekerja & 20 & 90 \\
& Primipara & 7 & 31,8 \\
& Multipara & 15 & 68,2 \\
\hline
\end{tabular}

Berdasarkan tabel 1 diatas dapat diketahui bahwa dari 22 responden sebagian besar 
responden berusia 20-35 tahun berjumlah 19 responden (86,4\%). Berdasarkan pekerjaan sebagian besar responden tidak bekerja berjumlah 22 responden $(99 \%)$ dan berdasarkan paritas sebagian besar responden adalah multipara berjumlah 15 responden $(68,2 \%)$.

Tabel 2. Keberhasilan Relaktasi Sebelum dan Sesudah Pijat Oksitosin dengan Aromaterapi Lavender

\begin{tabular}{|c|c|c|c|c|c|}
\hline \multirow{2}{*}{ Relaktasi } & \multicolumn{2}{|c|}{ Sebelum } & \multicolumn{2}{|c|}{ Sesudah } & \multirow{2}{*}{ Pvalue } \\
\hline & n & $\%$ & $\mathbf{n}$ & $\%$ & \\
\hline Berhasil & 0 & 0 & 18 & 81,8 & 0,000 \\
\hline Tidak berhasil & 22 & 100 & 4 & 18,2 & \\
\hline
\end{tabular}

Berdasarkan tabel 2 diatas dapat diketahui bahwa proporsi responden berdasarkan relaktasi sebelum intervensi adalah 22 responden (100\%) tidak berhasil dalam relaktasi, dan sesudah intervensi sebagian besar responden berhasil relaktasi yaitu 18 responden $(81,8 \%)$. Selanjutnya, analisis bivariat pada penelitian ini adalah analisis yang dilakukan untuk mengidentifikasi pengaruh antara variabel independen (pijat oksitosin dengan aromaterapi lavender) terhadap variabel dependen (relaktasi). Pengaruh variabel independen terhadap variabel dependen dilakukan dengan melihat hasil relaktasi sebelum dan sesudah intervensi.

Uji normalitas dalam penelitian ini berdasarkan hasil uji Shapiro-Wilk dengan menggunakan SPSS, karena uji ShapiroWilk digunakan untuk mengetahui sebaran data pada sampel penelitian yang berjumlah kurang dari 50. Hasil uji normalitas diperoleh p-value sebelum intervensi pijat oksitosin dan aromaterapi lavender yaitu 0,000 yang artinya tidak terdistribusi normal, untuk nilai p-value sesudah intervensi pijat oksitosin dan aromaterapi lavender yaitu 0,000 yang artinya tidak terdistribusi normal. Diperoleh hasil sebaran data sebelum dan sesudah dengan nilai p-value $<0,05$ artinya data tidak berdistribusi normal, selanjutnya dilakukan uji selisih untuk menentukan uji statistik yang tepat. Hasil uji analisis uji Wilcoxon, diperoleh nilai signifikansi sebesar 0,000 lebih kecil dari taraf signifikansi 5\% (pvalue $=0,000<0,05$ ) maka dapat dinyatakan ada pengaruh pemberian pijat oksitosin dengan aromaterapi lavender terhadap keberhasilan relaktasi pada ibu postpartum.

\section{Pembahasan}

Penelitian ini menyatakan bahwa sebagian besar responden berada pada rentang usia 20-35 tahun. Usia 20 tahun sampai 35 tahun merupakan usia poduktif bagi wanita untuk hamil dan melahirkan serta siap untuk menyusui bayinya. Umur sangat menentukan kesehatan maternal dan berkaitan dengan kesiapan secara fisik, mental dan psikologis dalam menghadapi kehamilan, persalinan, dan nifas serta cara mengasuh dan menyusui bayinya. ${ }^{11}$ Ibu hamil yang berusia 20-35 tahun merupakan usia yang matang dari segi reproduksi maupun pemikiran sehingga Ibu mampu menerima informasi yang baik bagi kesehatannya. ${ }^{12}$ Bertambahnya usia ibu akan mempengaruhi kemampuan intelektual ibu tersebut dalam menerima informasi, dan sebaliknya ibu yang mempunyai umur yang masih muda $(<20$ tahun) atau >35 tahun akan mempunyai sedikit kemampuan dalam menyaring informasi yang baru diterima tentang ASI Ekslusif. Semakin cukup usia ibu maka tingkat daya tangkap dan pola pikir ibu akan lebih matang dalam berfikir sehingga pengetahuan yang diperolehnya pun akan semakin baik. ${ }^{12}$

Hasil penelitian ini diketahui bahwa sebagian besar ibu tidak bekerja. Ibu tidak bekerja cenderung lebih fokus dalam merawat bayi dan keluarganya, sehingga dapat memberikan ASI secara maksimal. ${ }^{11}$ Dengan demikian, ibu tidak bekerja memiliki waktu yang lebih banyak untuk merawat anaknya dibandingkan ibu bekerja, yang harus berada di luar rumah dalam kurun waktu tertentu. ${ }^{11}$ Pekerjaan seseorang mempunyai pengaruh terhadap individu dalam berhubungan sosial terutama dalam berinteraksi dan bertukar informasi. Ibu yang bekerja di luar rumah akan mudah mendapatkan pengaruh dari 
kolega sehingga memudahkan ibu untuk mendapatkan masukan informasi pengalaman dan dapat merubah cara pandang ibu dalam menerima pengetahuan. ${ }^{13}$

Dari hasil penelitian diketahui mayoritas responden termasuk kategori multipara. Seorang ibu yang pernah menyusui pada kelahiran sebelumnya akan lebih mudah menyusui pada kelahiran berikutnya. Ibu dengan paritas dua atau lebih telah mempunyai pengalaman dalam menyusui dan merawat bayi. Keberhasilan ibu saat menyusui anak yang sekarang serta keyakinan ibu ini merangsang pengeluaran hormon oksitosin sehingga ASI dapat keluar dengan lancar. ${ }^{14}$

Salah satu faktor penghambat pemberian ASI eksklusif adalah penurunan produksi ASI. Penurunan produksi ASI pada hari-hari pertama setelah melahirkan dapat disebabkan oleh kurangnya rangsangan hormon prolaktin dan oksitosin yang sangat berperan dalam kelancaran produksi ASI. $^{14}$ Ketidaklancaran pengeluaran ASI pada hari-hari pertama setelah melahirkan dapat disebabkan oleh kurangnya rangsangan hormon oksitosin yang sangat berperan dalam kelancaran pengeluaran ASI. ${ }^{10}$

Penelitian ini menunjukkan ada pengaruh pemberian pijat oksitosin dengan aromaterapi lavender terhadap keberhasilan relaktasi pada ibu postpartum. Selama periode menyusui, produksi ASI sangat ditentukan oleh prinsip supply and demand artinya semakin sering payudara dikosongkan dan dihisap oleh bayi maka produksi ASI akan semakin bertambah. Akan tetapi, hal ini tidak berlaku pada 1-3 hari setelah kelahiran bayi. Pada saat tersebut produksi ASI lebih ditentukan oleh kerja hormon prolaktin sehingga diperlukan rangsangan baik berupa hisapan bayi maupun berupa perawatan payudara sehingga diperoleh kolostrum secara maksimal. ${ }^{14}$

Berdasarkan pernyataan Luthfiyana mengemukakan bahwa kerja hormon oksitosin sangat dipengaruhi perasaan dan pikiran ibu. Dengan demikian agar proses menyusui berjalan dengan lancar maka ibu harus dalam keadaan tenang, nyaman, dan senang saat menyusui. Namun, apabila ibu dalam keadaan stres maka refleks pengeluaran ASI dapat terhalangi. Stres pada ibu yang menyusui maka akan terjadi suatu blokade dari refleks let down. Hal ini disebabkan oleh karena adanya pelepasan dari adrenalin (epinefrin) yang menyebabkan vasokontriksi dari pembuluh darah alveoli, sehingga sekresi hormon oksitosin sedikit harapannya untuk dapat mencapai organ mioepitelium pada payudara. Akibat dari tidak sempurnanya refleks let down maka akan terjadi penumpukan ASI dampaknya dari mekanisme tersebut akan mengalami gangguan klinis tampak payudara membesar. Payudara yang besar dapat mengakibatkan gagal menyusui, rasa sakit, dan dapat menimbulkan peradangan yang dapat menyebabkan abses. Rasa sakit ini akan menjadi stres bagi seorang ibu menyusui, sehingga stres yang ada akan bertambah. Selain itu juga memiliki dampak terhadap bayi, akibat refleks let down tidak sempurna, maka bayi yang haus jadi tidak puas. Ketidakpuasan ini akan merupakan tambahan stres bagi ibunya. Bayi yang haus dan tidak puas ini, akan berusaha untuk dapat air susu yang cukup dengan cara menambah kuat isapannya sehingga tidak jarang dapat menimbulkan luka-luka pada puting susu dan sudah barang tentu luka-luka ini akan dirasakan sakit oleh ibunya yang juga akan menambah semakin stress. Hal ini akan menyebabkan terbentuk satu lingkaran setan yang tertutup (circulus vitiosus) dengan akibat kegagalan dalam menyusui. ${ }^{11}$

Hasil penelitian ini sesuai dengan penelitian yang dilakukan oleh Rohan, dkk yang menunjukkan produksi ASI pada ibu postpartum setelah diberikan intervensi pijat oksitosin, semua responden mempunyai produksi ASI lancar yang artinya ada pengaruh pijat oksitosin terhadap produksi ASI pada ibu postpartum. Pijat adalah suatu metode 
ilmiah memanipulasi dengan cara yang lembut terhadap otot tubuh sehingga menimbulkan efek yang spesifik, seperti memberikan kenyamanan dan menghilangkan rasa nyeri. Pemijatan memberikan pengaruh tubuh seperti pada sistem muskulo skeletal, pencernaan, perkemihan, pembuluh darah, limfa, endokrin dan syaraf. ${ }^{14}$

Pijat oksitosin adalah salah satu cara untuk menstimulasi keluarnya oksitosin dari kelenjar pituitary posterior. Frekuensi dilakukan pijat oksitosin juga dapat mempengaruhi produksi ASI. Wahyuningsih menyebutkan bahwa pijat oksitosin lebih efektif apabila dilakukan dua kali sehari yaitu tiap pagi dan sore hari. ${ }^{15}$ Dalam penelitian ini pijat oksitosin dengan aromaterapi lavender dilakukan dua kali sehari. Pada bagian atas tulang belakang diantara kedua bahu terdapat syaraf yang mempersarafi payudara. Pemijatan bagian atas punggung dapat membuat relaks bagian punggung dan meningkatkan pengeluaran ASI. Frekuensi dilakukan pijat oksitosin juga dapat mempengaruhi produksi ASI. Pijat oksitosin lebih efektif apabila dilakukan dua kali sehari yaitu tiap pagi dan sore hari. ${ }^{15}$ Pengeluaran ASI ini terjadi karena sel otot halus di sekitar alveoli mengerut sehingga memeras ASI untuk keluar. Penyebab otot-otot itu mengerut adalah suatu hormon yang dinamakan oksitosin. ${ }^{15}$

Melalui pijatan atau rangsangan pada tulang belakang, neurotransmitter akan merangsang medulla oblongata langsung mengirim pesan ke hypothalamus di hipofise posterior untuk mengeluarkan oksitosin dan mengalir melalui serabut syaraf (neurotransmiter) pada tulang belakang yang mengontrol tekanan darah, nadi dan bagian sistem syaraf otonom. Oksitosin mempengaruhi sel-sel mioepitel yang mengelilingi alveoli mammae sehingga alveoli berkontraksi dan mengeluarkan air susu yang sudah disekresikan oleh kelenjar mammae. Pemijatan di daerah tulang belakang ini juga akan merileksasi ketegangan dan menghilangkan stress dan dengan begitu hormon oksitosin keluar dan akan membantu pengeluaran air susu ibu, dibantu dengan isapan bayi pada puting susu pada saat segera setelah bayi lahir dengan keadaan bayi normal. Hormon oksitosin mempengaruhi dua target yaitu uterus dan payudara. Pada saat melahirkan oksitosin meningkat kontraksi terus, setelah melahirkan menstimulasi pengeluaran ASI dari kelenjar payudara, dimana stimulus tersebut diperpanjang dengan hisapan bayi. ${ }^{16}$ Hasil penelitian ini juga penelitian Setiowati dalam penelitiannya yang menyebutkan bahwa produksi ASI pada ibu postpartum setelah diberikan intervensi pijat oksitosin, semuanya mempunyai produksi ASI lancar dan hasil uji statistik diperoleh $\mathrm{p}$ - value $=0,042(\mathrm{p}$ value $<0,05)$ yang artinya ada pengaruh pijat oksitosin terhadap produksi ASI pada ibu postpartum. ${ }^{17}$

\section{Kesimpulan}

Simpulan dari penelitian ini adalah pijat oksitosin dan aromaterapi lavender mempunyai pengaruh terhadap keberhasilan relaktasi. Peran tenaga kesehatan, khususnya bidan sangatlah penting dan hendaknya dapat menerapkan pijat oksitosin dan aromaterapi lavender untuk meningkatkan keberhasilan relaktasi agar cakupan ASI Eklusif tercapai, memberikan pendidikan kesehatan tentang cara relaktasi dengan pijat oksitosin dan aromaterapi lavender dan perlunya memberikan pendidikan kesehatan serta dukungan pada keluarga untuk melakukan terapi komplementer dengan pijat oksitosin dan aromaterapi untuk meningkatkan keberhasilan relaktasi. Peningkatan keberhasilan relaktasi akan berperan dalam pencapaian Indikator keluarga sehat sehingga dapat menyukseskan program Indonesia Sehat. Peneliti selanjutnya diharapkan mengkaji berbagai sumber maupun referensi yang terkait dengan relaktasi, dan menambah waktu penelitian agar lebih lama lagi sehingga dapat diketahui bahwa relaktasi berjalan dalam 
waktu yang lama atau hingga bayi berusia lebih dari enam bulan atau sudah melewati batas ASI eksklusif.

\section{Ucapan Terima Kasih}

Terima kasih kami sampaikan kepada LLDIKTI Wilayah IV, yang telah memberikan hibah penelitian dosen pemula tahun anggaran 2020. Terima Kasih juga kami sampaikan kepada BPM Bidan Eli Liawati, S.ST yang telah memberikan izin untuk menggunakan lahan praktiknya untuk menjadi lahan penelitian. Terima kasih kepada Akademi kebidanan Al-Ikhlas yang telah memberikan kesempatan untuk mengikuti hibah penelitian dosen pemula sehingga artikel ini bisa diselesaikan.

\section{Daftar Pustaka}

1. Monika FB. Buku pintar ASI dan menyusui. Jakarta: Noura Books; 2015.

2. World Health Organization. Pekan Menyusui Dunia: UNICEF dan WHO menyerukan Pemerintah dan Pemangku Kepentingan agar mendukung semua ibu menyusui di Indonesia selama COVID-19. 2020. [cited 2020 Agust 25] Available from https://www.who.int/indonesia/news/detail/0308-2020

3. Winter, Lori Feldman, dkk. Data show breastfeeding rates improving but disparities exist. 2020. [cited 2020 Nov 1] Available from https://www.aappublications.org/news/

4. United Nations Children's Fund. Laporan Baseline SDG tentang anak anak di Indonesia. 2017. [cited 2020 Maret 1] Available from https://www.unicef.org/indonesia/media/1471/f ile/SDG

5. Profil kesehatan Jawa Barat tahun 2017. AKI dan AKB provinsi Jawa Barat. 2017. [cited 2020 Mar 17] Available from http://diskes.jabarprov.go.id/dmdocuments/

6. Cho, Su Jin., Hye Kyoung Cho., Hee Sook Lee \& Keun Lee. Factor related to success in relactation., J Korean Soc Neonatol, Seoul. , 2015.

7. Astutik RY. Asuhan kebidanan masa nifas dan menyusui. Jakarta: CV. Trans Info Media; 2015.

8. Pilaria E dan Sopiatun R. Pengaruh pijat oksitosin terhadap produksi ASI pada ibu post partum di wilayah kerja Puskesmas Pejeruk Kota Mataram tahun 2017.2018. [cited 2020 Mar 19] Available from https://www.academicjourn sal.yarsi.ac.id/index.php/jurnal-fkyarsi/article

9. Laura DD, dkk. Efektifitas aroma terapi lavender terhadap kualitas tidur ibu post partum.2015. [cited 2020 Mar 26] Available from https://www. media.neliti.c om/media/publications.

10. Zahra A. Pengaruh pijat oksitosin dengan aromaterapi lavender terhadap produksi ASI pada Ibu porstpartum di BPM Kota Palembang tahun 2018. Kemenkes RI Poltekes Diploma IV Kebidanan. 2019

11. Luthfiyana NU. Perbedaan pijat oksitosin dan breast care terhadap jumlah ASI pada Ibu Postpartum. Penelitian tidak dipublikasikan. Fakultas Kedokteran Universitas Sebelas Maret. 2015.

12. Qudsiah SC, Djarot HS dan Nurjanah S. Hubungan antara paritas dan umur Ibu dengan kejadian anemia pada ibu hamil trimester III Tahun 2015. Jurnal Kebidanan Vol 2 No 1 2015. Fakultas Ilmu Keperawatan dan Kesehatan.Universitas Muhammadiyah Semarang. 2015

13. Kusumawati \& Hartono. Buku ajar keperawatan, Jakarta: Salemba; 2015.

14. Rohan HH, Setyowati A, Herdyana E, Komariyah S, dan Agustina E. Buku kesehatan reproduksi: pengenalan penyakit menular reproduksi dan pencegahan.Malang: Intimedia, pp. 150-160. 2017

15. Wahyuningsih M. Efektifitas aromaterapi lavender (Lavandula Angustifolia) dan massage effleurage terhadap tingkat nyeri persalinan kala I fase aktif pada primigravida di BPS Utami dan ruang PONEK RSUD Karanganyar. Skripsi Stikes Kusuma Husada Surakarta diakses pada 20 Desember 2016

16. Machmudah dan Khayati N. Produksi ASI Ibu post seksio sesarea dengan pijat oketani. JurnalNers Vol. 9 No. 1 April 2014: 104-110. 2015

17. Setiowati W. Hubungan pijat oksitosin dengan kelancaran produksi ASI pada Ibu post partum fisiologis Hari Ke 2-3, Jurnal Darul Azhar,Vol 3 No 1, diakses pada tanggal 16 Januari 2018, http://jurnal-kesehatan.id.2017 